\title{
ON TRIPLE SEQUENCE SPACE OF BERNSTEIN STANCU CHENEY AND SHARMA OPERATOR OF ROUGH $I_{\lambda}$-CONVERGENCE OF WEIGHT $g$
}

\author{
ARULMANI INDUMATHI, AYHAN ESI, and NAGARAJAN SUBRAMANIAN
}

\begin{abstract}
We introduce and study some basic properties of rough $I_{\lambda}$-convergence of weight $g$, where $g: \mathbb{N}^{3} \rightarrow[0, \infty)$ is a function statisying $g(n) \rightarrow \infty$ and $g(n) \not \rightarrow 0$ as $n \rightarrow \infty$ of a triple sequence of Bernstein Stancu Cheney and Sharma operators and also investigate certain properties of rough $I_{\lambda}$-convergence of weight $g$.
\end{abstract}

MSC 2010. 40F05, 40J05, 40G05.

Key words. Triple sequences, rough convergence, closed and convex, cluster points and rough limit points, Bernstein Cheney and Sharma operators, Istatistical convergence of order $g, I_{\lambda}$-statistical convergence of weight $g$.

\section{REFERENCES}

[1] S. Aytar, Rough statistical convergence, Numer. Funct. Anal. Optim., 29 (2008), $291-$ 303.

[2] S. Aytar, The rough limit set and the core of a real sequence, Numer. Funct. Anal. Optim., 29 (2008), 283-290.

[3] A. Esi, On some triple almost lacunary sequence spaces defined by Orlicz functions, Research and Reviews: Discrete Mathematical Structures, 1 (2014), 16-25.

[4] A. Esi and M. Necdet Catalbas, Almost convergence of triple sequences, Global Journal of Mathematical Analysis, 2 (2014), 6-10.

[5] A. Esi and E. Savas, On lacunary statistically convergent triple sequences in probabilistic normed space, Appl. Math. Inf. Sci., 9 (2015), 2529-2534.

[6] A. Esi, S. Araci and M. Acikgoz, Statistical convergence of Bernstein operators, Appl. Math. Inf. Sci., 10 (2016), 2083-2086.

[7] A. Esi, N. Subramanian and A. Esi, On triple sequence space of Bernstein-Stancu operator of rough $I_{\lambda}$ statistical convergence of weighted $g(A)$, Ann. Fuzzy Math. Inform., 16 (2018), 337-361.

[8] S. Debnath, B. Sarma and B.C. Das, Some generalized triple sequence spaces of real numbers, J. Nonlinear Anal. Optim., 6 (2015), 71-79.

[9] A.J. Dutta, A. Esi and B.C. Tripathy, Statistically convergent triple sequence spaces defined by Orlicz function, J. Math. Anal., 4 (2013), 16-22.

[10] E. Dündar and C. Cakan, Rough I-convergence, Demonstr. Math., 47 (2014), 638-651.

The authors are extremely grateful to the anonymous learned referee(s) for their keen reading, valuable suggestion and constructive comments for the improvement of the manuscript.

DOI: $10.24193 /$ mathcluj.2021.1.09 
[11] M. Jeyam Bharathi, S. Velmurugan, N. Subramanian and R. Srikanth, On triple sequence space of Bernstein operator of rough $I_{\lambda}$-statistical convergence of weighted $g(A)$, Journal of intelligent and fuzzy systems, 36 (2019), 13-27.

[12] H.X. Phu, Rough convergence in normed linear spaces, Numer. Funct. Anal. Optim., 22 (2001), 199-222.

[13] H.X. Phu, Rough continuity of linear operators, Numer. Funct. Anal. Optim., 23 (2002), $139-146$

[14] H.X. Phu, Rough convergence in infinite dimensional normed spaces, Numer. Funct. Anal. Optim., 24 (2003), 285-301.

[15] A. Sahiner, M. Gurdal and F.K. Duden, Triple sequences and their statistical convergence, Selçuk J. Appl. Math., 8 (2007), 49-55.

[16] A. Sahiner and B. C. Tripathy, Some I-related properties of triple sequences, Selçuk J. Appl. Math., 9 (2008), 9-18.

[17] N. Subramanian and A. Esi, The generalized tripled difference of $\chi^{3}$ sequence spaces, Global Journal of Mathematical Analysis, 3 (2015), 54-60.

[18] N. Subramanian, A. Esi and A. Indumathi, Stancu type of Cheney and Sharma operators of Pascal rough triple sequences, Communications in Nonlinear Analysis, 6 (2019), 6477.

Received May 13, 2019

Accepted November 7, 2019

\author{
SASTRA Deemed to be University \\ School of Arts Sciences and Humanities \\ Department of Mathematics \\ Thanjavur-613 401, India \\ E-mail: nsmaths@yahoo.com \\ https://orcid.org/0000-0003-3249-6525 \\ Malatya Turgut Ozal University \\ Engineering Faculty \\ Department of Basic Engineering Sciences \\ 44040 Malatya, Turkey \\ E-mail: aesi23@hotmail.com \\ https://orcid.org/0000-0003-3137-3865 \\ SASTRA Deemed to be University \\ School of Arts Sciences and Humanities \\ Department of Mathematics \\ Thanjavur-613 401, India \\ E-mail: nsmaths@gmail.com \\ https://orcid.org/0000-0002-5895-673X
}

